\title{
O ESTADO DA ARTE SOBRE AS INVESTIGAÇÕES PRODUZIDAS PELOS ESTAGIÁRIOS DE GEOGRAFIA NO PERÍODO DE 2011.1 A 2013.2
}

\author{
$\underline{\text { Autor }^{1}}$; EDILEUSA AMARAL, Bolsista PROBIC/, Graduada em Geografia - Universidade Estadual de Feira de \\ Santana, e-mail: jaspe_ed@hormail.com \\ 2. Orientador; MARIA BRAGA - Departamento de Educação - Universidade Estadual de Feira de Santana, e- \\ mail: nicebraga08@hotmail.com
}

\section{PALAVRAS-CHAVE: Estágio Supervisionado; Geografia; Estagiário,}

\section{INTRODUÇÃO}

A presente pesquisa é o resultado de um estudo realizado com quarenta e nove (42) artigos de conclusão de Estágio Supervisionado do curso de licenciatura em Geografia da Universidade Estadual de Feira de Santana no período de 2011.1 a 2013.2. A educação escolar é uma das grandes responsáveis pela transformação e desenvolvimento social, e nesse contexto o desenvolvimento de pesquisas na educação é de grande relevância para melhoria do sistema educacional de uma nação. O componente curricular de Estágio Supervisionado em licenciatura da Universidade Estadual de Feira de Santana é feito em 400 horas, divididas em quatro disciplinas de 100 horas/aula cada: EDU 334- Estágio Supervisionado em Geografia I, EDU 335- Estágio Supervisionado em Geografia II, EDU 336- Estágio Supervisionado em Geografia III e EDU 337- Estágio Supervisionado em Geografia IV.No Estágio Supervisionado em Geografia I, é a observação onde aluno estagiário visita uma escola e procura conhecer toda a dinâmica do seu cotidiano: O espaço físico, suas dependências, ás áreas de lazer, esportes, observa a movimentação dos alunos, as conversas nos intervalos, as brincadeiras, a hora do recreio, a atuação da coordenadora do colégio, as movimentações dos alunos nos corredores, a quadra esportiva e as salas de aula. A atuação da professora tentando manter os alunos acomodados e em silêncio para que a aula fosse ministrada etc. O Estágio Supervisionado em Geografia II de coparticipação, o aluno já participa de algumas atividades em sala com o professor regente. O Estágio Supervisionado em Geografia III, de regência, o aluno estagiário assume uma turma por uma unidade ou se necessário duas, porém, com a supervisão do professor regente. É nessa fase que este futuro professor conhece a realidade da profissão de professor de fato. Pimenta \& Lima, (2004). O exercício de qualquer profissão é prático, no sentido de que se trata de aprender a fazer "algo" ou "ação". A profissão de professor também é prática. E o modo de aprender a profissão, conforme a perspectiva da imitação, reprodução e, às vezes, reelaboração dos modelos existentes na prática consagradas como bons. O estágio, também, por meio da pesquisa e investigação abre possibilidades para o futuro professor compreender as situações vivenciadas e observadas nas escolas e seus respectivos sistemas de ensino, formando assim professores críticos-reflexivos e pesquisadores. Nessa perspectiva, os cursos de formação, por meio do estágio, devem valorizar as atividades que desenvolvem capacidades e habilidades de diálogo, reflexão, pesquisa, investigação e análises críticas dos contextos educativos. Sendo assim, o estágio surge como um processo fundamental na formação do aluno estagiário. Este é um momento de formação em que o graduando pode vivenciar experiências, conhecer melhor sua futura área de atuação, de tal modo que sua formação se torna mais significativa. No entendimento de Ghedin (2015), o estágio enquanto momento de articulação teoria-prática é formador de dimensão científica /técnica, política, ética e estética do futuro professor. A dinâmica de um ambiente escolar é rica em informações que pode despertar interesse para investigação. Investir em pesquisa, é incentivar novas formas de ensinar e aproximar o aluno para novas perspectivas de mudanças, inovações e melhorias na educação (GHEDIN, 2015). 
Compreende-se que é nesse tempo/espaço que o professor em formação constrói sua identidade profissional. Nesse sentido, o estágio constitui-se numa formação que é de natureza ontológica, isto é, compõe o que será o professor identidade profissional.

\section{METODOLOGIA}

\section{O ESTADO DA ARTE PARA A PESQUISA ACADÊMICA}

Esse é um estudo do tipo estado da arte que é um método de pesquisa que se realiza por meio de uma revisão bibliográfica sobre a produção de uma temática em determinada área de conhecimento. Uma característica importante do Estado da Arte é o recorte temático, pois serve para definir e delimitar o que buscamos investigar, possibilitando ao pesquisador fazer as análises mais aprofundadas visando aperfeiçoamento e sugerindo mudanças. Esta pesquisa analisou os artigos de conclusão da disciplina de Estágio Supervisionado em Geografia das turmas formadas dos semestres 2011.1 a 2013.2. Os trabalhos abordam problemáticas percebidas ou vivenciadas pelos alunos/estagiários no ambiente escolar durante as 400 horas de estágio. Inicialmente fizemos a coleta dos trabalhos de conclusão do estágio com os professores responsáveis pela disciplina dos semestres 2011.1 a 2013.2, ou seja, material produzido nos últimos 24 meses. O estudo foi realizado através de uma abordagem qualiquantitativa pois os trabalhos foram organizados por categoria para em seguida serem analisados, minuciosamente. As análises do material foram realizadas através de uma leitura mais aprofundada de algumas partes do artigo como: A temática, os objetivos, a justificativa e em alguns casos o artigo completo. Essas leituras foram bem criteriosas observando as problemáticas vivenciadas pelos estagiários durante o componente curricular em questão. Sendo assim, foi possível criar as categorias: 1- Pesquisa e Docência, 2 - Estratégias de Ensino/Recursos Didáticos, 3 - Reflexão da Identidade Docente, 4 - Prática Pedagógica, 5 Linguagem Cartográfica, 6 - Formação Docente, 7 - Avaliação da Aprendizagem, oito Educação Inclusiva - 9 - Evasão Escolar.

\section{RESULTADOS E/OU DISCUSSÃO}

A categoria de maior relevância foi Estratégias de ensino e recursos didáticos com um percentual de $70 \%$.

Tabela 1. Classificação Das Categorias de Análises Por Temáticas

\begin{tabular}{|l|c|}
\hline Pesquisa e Docência & 2 \\
\hline Estratégia de Ensino/Recursos Didáticos & 28 \\
\hline Linguagem cartográficas/Ensino & 3 \\
\hline A Prática Pedagógica & 2 \\
\hline Reflexão sobre a Identidade Docente & 1 \\
\hline Formação Docente & 2 \\
\hline Avaliação da Aprendizagem & 1 \\
\hline Educação Inclusiva & 1 \\
\hline Bullying nas Escolas Públicas & 1 \\
\hline Evasão Escolar & 1 \\
\hline
\end{tabular}

Dentro da categoria estratégia de ensino e recursos didáticos, foi possível fazer algumas subdivisões. Em primeiro lugar destacaram-se os trabalhos voltados para a temática das novas 
tecnologias no ensino de geografia. Esses trabalhos abordaram situações vivenciadas pelos estagiários em suas diferentes fases do estagio I, II, III e IV. As tecnologias da informação e comunicação são ferramentas importantes no auxílio na construção do conhecimento de forma dinâmica, diferenciada, prazerosa e motivacional. Em um dos trabalhos analisados, o estagiário discutiu a importância do planejamento, numa perspectiva de transformação da realidade. Para ele, as ações de planejamento devem ser acompanhadas de constantes reflexões, isso porque a escola é um campo de atuação em constante mudança. Em sua perspectiva, a ausência de um planejamento sobre o uso das tecnologias educacionais pode ser fator determinante para o uso inadequado do recurso oferecido por esta ferramenta. Uma das atividades mais utilizadas pelos educadores da escola onde este estagiário fez a regência é a exposição de aulas em Power Point, com a presença de imagens e vídeos. Em sua visão, a simples exposição de conteúdos por meio de recursos tecnológicos, não caracteriza um processo de interatividade entre professor e aluno tendo em vista que usar o computador como um simples 'quadro-negro' ou um 'clicar' de páginas, não gera motivação e nem explora todo o potencial deste recurso. Em outros dois trabalhos analisados, os estágios perceberam que às estratégias de ensino com as tecnologias ainda é muito insignificante diante de uma realidade tão avançada como está hoje o mundo Ciberespaço. De acordo com esses trabalhos, eles acreditam que o uso das ferramentas de maneira eficiente trará ganhos significativos nas aulas de geografia. Outra questão levantada nesses trabalhos foi à instalação de programas obsoletos, pouco conhecidos pelos alunos dificultando o manuseio destes. Também a insuficiência de computadores para atender a demanda da escola é outra dificuldade apresentada nos trabalhos. As ferramentas tecnológicas auxiliam e influenciam o cotidiano da sociedade. Portanto, as escolas precisam acompanhar e inserir as novas tecnologias dentro de seu programa educacional, para não correr o risco de cair no atraso funcional do ensino obsoleto. Elas precisam articular entre o conhecimento elaborado e os temas da vida cidadão.

Outro grupo de trabalho se voltou para o livro didático no ensino de geografia. Num desses trabalhos, o estagiário traz uma problemática acerca do tema rural proposto nos livros didáticos. Essa temática, muito discutida em algumas disciplinas dentro da universidade, aparece nos livros de forma muito diferente, ou seja, o rural proposto nos livros didáticos foge muito das características do aluno local. Observa-se nesse trabalho, que os alunos, apesar de considerarem mais cômodo apenas a utilização do livro nas aulas, afirmaram que outros recursos aliados ao livro didático tornavam as aulas mais dinâmicas e inclusive faziam com que aprendessem melhor o conteúdo estudado.

\section{CONSIDERAÇÕES FINAIS}

O objetivo geral da pesquisa foi levantar o estado da arte sobre as investigações feitas pelos estagiários de Geografia, no período de 2011.1 a 2013.2. Com isso, buscamos compreender as problemáticas abordadas nos artigos de conclusão do curso de licenciados em Geografia da Universidade Estadual de Feira de Santana-UEFS. As análises do material foram realizadas através de uma leitura mais aprofundada de algumas partes do artigo como: A temática, os objetivos, a justificativa e em alguns casos o artigo completo. Essas leituras foram bem criteriosas observando as problemáticas vivenciadas pelos estagiários durante o componente curricular em questão. Sendo assim, foi possível selecionar as categorias: 1- Pesquisa e Docência, 2 - Estratégias de Ensino/Recursos Didáticos, 3 - Reflexão da Identidade Docente, 4 - Prática Pedagógica, 5 - Linguagem Cartográfica, 6 - Formação Docente, 7 - Avaliação da Aprendizagem, oito - Educação Inclusiva - 9 - Evasão Escolar. A categoria de maior relevância foi Estratégias de ensino e recursos didáticos com um total de $70 \%$. Com o trabalho esperamos oferecer um material fonte de dados, informações e conhecimentos para futuros pesquisadores - estudantes, professores, gestores - que realizem investigações sobre as instituições envolvidas no trabalho. 


\section{REFERÊNCIAS}

ANASTASIOU, Léa das Graças Camargo; ALVES, Leonir Pessate (Orgs.). Processos de Ensinagem na universidade. Pressupostos para as estratégias de trabalho em aula. 3. ed. Joinville: Univille, 2004. P. 67-100.

CAVALCATI, Lana de Souza. Geografia, escola e construção de conhecimentos. 16. ed. Campinas, SP: Papirus, 2010.

FERREIRA, N. S. de A. As pesquisas denominadas "estado da arte". Educação \& Sociedade, Campinas, ano XXIII, nº. 79, p. 257-272, 2002.

GHEDIN, E; OLIVEIRA, E. S.; ALMEIDA, W. A. Estágio com Pesquisa. São Paulo: Cortez, 2015.

NAPOLITANO, Marcos. Como usar o cinema em sala de aula. São Paulo: Contexto, 2006. PIMENTA, Selma Garrido; LIMA, Maria Socorro Lucena. Estágio e Docência. São Paulo: Cortez, 2004. 